\title{
TU/e EN⿴HONE

\section{Design and characterization of a prototype divertor viewing infrared video bolometer for NSTX-U}

\section{Citation for published version (APA):}

van Eden, G. G., Reinke, M. L., Peterson, B. J., Gray, T. K., Delgado-Aparicio, L. F., Jaworski, M. A., Lore, J., Mukai, K., Sano, R., Pandya, S. N., \& Morgan, T. W. (2016). Design and characterization of a prototype divertor viewing infrared video bolometer for NSTX-U. Review of Scientific Instruments, 87(11), 1-4. [11D402]. https://doi.org/10.1063/1.4955487

DOI:

$10.1063 / 1.4955487$

Document status and date:

Published: 01/11/2016

\section{Document Version:}

Publisher's PDF, also known as Version of Record (includes final page, issue and volume numbers)

\section{Please check the document version of this publication:}

- A submitted manuscript is the version of the article upon submission and before peer-review. There can be important differences between the submitted version and the official published version of record. People interested in the research are advised to contact the author for the final version of the publication, or visit the $\mathrm{DOI}$ to the publisher's website.

- The final author version and the galley proof are versions of the publication after peer review.

- The final published version features the final layout of the paper including the volume, issue and page numbers.

Link to publication

\section{General rights}

Copyright and moral rights for the publications made accessible in the public portal are retained by the authors and/or other copyright owners and it is a condition of accessing publications that users recognise and abide by the legal requirements associated with these rights.

- Users may download and print one copy of any publication from the public portal for the purpose of private study or research.

- You may not further distribute the material or use it for any profit-making activity or commercial gain

- You may freely distribute the URL identifying the publication in the public portal.

If the publication is distributed under the terms of Article 25fa of the Dutch Copyright Act, indicated by the "Taverne" license above, please follow below link for the End User Agreement:

www.tue.nl/taverne

Take down policy

If you believe that this document breaches copyright please contact us at:

openaccess@tue.nl

providing details and we will investigate your claim. 


\section{Design and characterization of a prototype divertor viewing infrared video bolometer for NSTX-U}

G. G. van Eden, M. L. Reinke, B. J. Peterson, T. K. Gray, L. F. Delgado-Aparicio, M. A. Jaworski, J. Lore, K. Mukai, R. Sano, S. N. Pandya, and T. W. Morgan

Citation: Rev. Sci. Instrum. 87, 11D402 (2016); doi: 10.1063/1.4955487

View online: http://dx.doi.org/10.1063/1.4955487

View Table of Contents: http://aip.scitation.org/toc/rsi/87/11

Published by the American Institute of Physics

\section{SHIMADZU Powerful, Multi-functional UV-Vis-NIR and}

\section{Excellence in Science $F J\}$ Spectsophotometers}

Providing the utmost in sensitivity, accuracy and resolution for applications in materials characterization and science

- Photovoltaics

- Polymers

- Coatings

- Ceramics

- Thin films

- Inks

- DNA film structures

- Packaging materials

- Nanotechnology

Click here for accurate, cost-effective laboratory solutions

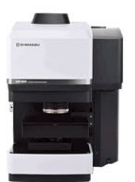

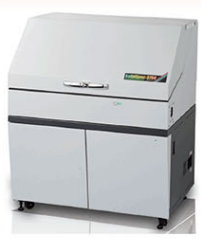




\title{
Design and characterization of a prototype divertor viewing infrared video bolometer for NSTX-U
}

\author{
G. G. van Eden, ${ }^{1}$ M. L. Reinke, ${ }^{2}$ B. J. Peterson, ${ }^{3}$ T. K. Gray, ${ }^{2}$ L. F. Delgado-Aparicio, ${ }^{4}$ \\ M. A. Jaworski, ${ }^{4}$ J. Lore,${ }^{2}$ K. Mukai, ${ }^{3}$ R. Sano, ${ }^{5}$ S. N. Pandya,${ }^{6}$ and T. W. Morgan ${ }^{1}$ \\ ${ }^{1}$ Dutch Institute for Fundamental Energy Research, 5612 AJ Eindhoven, The Netherlands \\ ${ }^{2}$ Oak Ridge National Laboratory, Oak Ridge, Tennessee 37831, USA \\ ${ }^{3}$ National Institute for Fusion Science, Toki 509-5292, Japan \\ ${ }^{4}$ Princeton Plasma Physics Laboratory, P.O. Box 451, Princeton, New Jersey 08543, USA \\ ${ }^{5}$ National Institutes for Quantum and Radiological Science and Technology, Naka 311-0193, Japan \\ ${ }^{6}$ Institute for Plasma Research, Bhat Village, Gandhinagar, 382428 Gujarat, India
}

(Presented 6 June 2016; received 6 June 2016; accepted 19 June 2016;

published online 12 July 2016)

The InfraRed Video Bolometer (IRVB) is a powerful tool to measure radiated power in magnetically confined plasmas due to its ability to obtain $2 \mathrm{D}$ images of plasma emission using a technique that is compatible with the fusion nuclear environment. A prototype IRVB has been developed and installed on NSTX-U to view the lower divertor. The IRVB is a pinhole camera which images radiation from the plasma onto a $2.5 \mu \mathrm{m}$ thick, $9 \times 7 \mathrm{~cm}^{2} \mathrm{Pt}$ foil and monitors the resulting spatio-temporal temperature evolution using an IR camera. The power flux incident on the foil is calculated by solving the $2 \mathrm{D}+$ time heat diffusion equation, using the foil's calibrated thermal properties. An optimized, high frame rate IRVB, is quantitatively compared to results from a resistive bolometer on the bench using a modulated $405 \mathrm{~nm}$ laser beam with variable power density and square wave modulation from $0.2 \mathrm{~Hz}$ to $250 \mathrm{~Hz}$. The design of the NSTX-U system and benchtop characterization are presented where signal-to-noise ratios are assessed using three different IR cameras: FLIR A655sc, FLIR A6751sc, and SBF-161. The sensitivity of the IRVB equipped with the SBF-161 camera is found to be high enough to measure radiation features in the NSTX-U lower divertor as estimated using SOLPS modeling. The optimized IRVB has a frame rate up to $50 \mathrm{~Hz}$, high enough to distinguish radiation during edge-localized-modes (ELMs) from that between ELMs. Published by AIP Publishing. [http://dx.doi.org/10.1063/1.4955487]

\section{INTRODUCTION}

Measurements of the radiated power in the boundary of magnetically confined plasmas are critical for studying the physics of detachment and confirming the overall power balance. The InfraRed Video Bolometer (IRVB) diagnostic, tested extensively on the LHD and JT-60U devices, has been demonstrated to be a useful alternative or complement to conventional resistive bolometers. ${ }^{1,2}$ NSTX-U ${ }^{3}$ is presently not equipped with absolute radiated power measurements and is exploring multiple techniques to accomplish a variety of core and boundary physics missions, motivating demonstrations of an IRVB. A prototype IRVB, designed to provide a 1D poloidal view of the lower NSTX-U divertor, has been extensively investigated on the benchtop and is currently being deployed for testing during the 2016 experimental campaign.

The IRVB concept relies on heating of a thin metal foil by absorbing radiation from the plasma where temperature changes measured by an IR camera are used to solve the 2D heat equation yielding the radiative power flux impinging on the foil. ${ }^{4}$ While data interpretation and calibration of the IRVB are more complicated than that of resistive bolometers, the

Note: Contributed paper, published as part of the Proceedings of the 21st Topical Conference on High-Temperature Plasma Diagnostics, Madison, Wisconsin, USA, June 2016. technique is attractive due to the avoidance of electrical pickup and the cost reduction possible due to the IRVB's increased bolometer channels per area. There is particular motivation in boundary plasma studies where the $2 \mathrm{D}$ radiation distribution near the $\mathrm{x}$-point region of the tokamak would benefit from increased spatial resolution and when non-axisymmetric fields are used to create $3 \mathrm{D}$ radiation structures.

The IRVB hardware design, signal-to-noise ratio (SNR), and temporal response of the system are discussed hereafter. The performance of three different IR cameras with unique spatial and temporal specifications is quantitatively compared, demonstrating the SNR and temporal response of the IRVB at expected NSTX-U signals. The overall detection limits of the NSTX-U IRVB are finally compared to those of conventional resistive bolometers. A primary objective of the prototype is to explore the temporal resolution limits of the IRVB in order to confidently distinguish radiation during edge localized modes (ELMs) from that between ELMs. Scoping the camera performances is expected to aid future IRVB optimization and upgrades.

\section{IRVB DESIGN FOR NSTX-U}

\section{A. Hardware}

The IRVB is installed on the Bay-J upper port of NSTX$\mathrm{U}$, angled $75^{\circ}$ with respect to the horizontal axis. A poloidal 
view of the entire lower divertor and part of the center stack is obtained using this position, as shown in Fig. 1(c). While the diagnostic is capable of imaging $2 \mathrm{D}$ radiation patterns, the field of view (FOV) is restricted to a single poloidal fan due to the in-vessel passive plate structures of NSTX-U. The basic hardware design is shown in Figs. 1(a) and 1(b) and consists of an 8 in. nipple section attached to a $6 \mathrm{in}$. nipple where the $\mathrm{Pt}$ foil detector flange is mounted between these parts. While nearly all previous IRVB designs utilized re-entrant layouts, this design was made to be attached directly to a gate valve, allowing installation after the main vacuum chamber is pumped down. The $\mathrm{Cu}$ plates holding the $\mathrm{Pt}$ foil in place are mounted in the center of a 8 in. to 6 in. zero-length adapter piece while an offset provides pressure relief between the chambers. The $2.5 \mu \mathrm{m}$ thick Pt foil ${ }^{5}$ of dimensions $9 \times 7 \mathrm{~mm}^{2}$ is calibrated on the bench to yield the spatially resolved thermal conductivity, diffusivity, and emissivity. ${ }^{6}$ An aperture flange is mounted on the front end, built directly into a double-sided flange which mates to the gate valve, while a 3 in. clear aperture Del Mar Photonics ZnSe window is mounted on the back end of the diagnostic. The aperture has dimensions $7.5 \times 2.75 \mathrm{~mm}^{2}$. The whole interior as well as both sides of the foil is blackened using Aerodag- $G$ graphite spray, reducing stray-light reflections. The camera is located $43.8 \mathrm{~cm}$ from the foil and is set by the distance required to fully image the rectangular foil by the camera when using a $25 \mathrm{~mm}$ lens. Liquid nitrogen cooling requires the camera to be mounted horizontally and a gimbal mounted mirror is necessary to project the foil image on the camera. The IRVB is pumped through the aperture down to the mTorr range followed by pumping through the foil chamber to reach UHV. A Santa Barbara Focal Plane SBF-161 IR camera is being used for the prototype IRVB. This camera is sensitive to $2-12 \mu \mathrm{m}$ radiation ( $8-12 \mu \mathrm{m}$ using a Janos Tech. Varia $25 \mathrm{~mm}$ lens), has $128 \times 128$ pixels, and can collect full frame images at $1.6 \mathrm{kHz}$. No magnetic shielding is required and the camera itself is non-magnetic.

\section{B. Expected power levels in NSTX-U}

Camera pixels are averaged as to obtain a 1D array consisting of 30 bolometer super-pixels (channels) of $7.5 \times 2.11 \mathrm{~mm}^{2}$. SOLPS ${ }^{8}$ modeling of a NSTX-U density scan $\left(\mathrm{n}_{\mathrm{e}}=0.2-1.0 \times 10^{20} \mathrm{~m}^{-3}\right)$ with $10 \mathrm{MW}$ of input power was used to scope estimated signal levels. Within this scan, simulations predict movement of narrow radiation features in the NSTX-U divertor and development of a MARFE-like radiation structure along the inner wall. Integration of the predicted emissivities along the IRVB sight lines, accounting for finite viewing cone geometry, yields IRVB signal levels in the range $0.2-190 \mathrm{~W} \mathrm{~m}^{-2}$, as shown in Fig. 2, and above the estimated noise equivalent power density $<2 \mathrm{~W} \mathrm{~m}^{-2}$. These simulations do not include contributions from core radiation which outside of on-axis impurity accumulation is expected to be present but at a much lower level based on results from resistive bolometer diagnostics with similar viewing geometries.

\section{BENCHTOP TESTING OF FREQUENCY AND POWER RESPONSE}

The response of the IRVB to the range of power densities estimated from SOLPS was investigated by exposing the foil to a $\sim 5 \mathrm{~mW}$ laser (Global Laser BlueLyte), emitting at $405 \mathrm{~nm}$ capable of modulation up to $750 \mathrm{kHz}$ using an external function generator. A vacuum window mounted to the aperture plate in place of the gate valve sealed the diagnostic and foreline pumping allowed the pressure in the IRVB chamber to a) Exploded Design

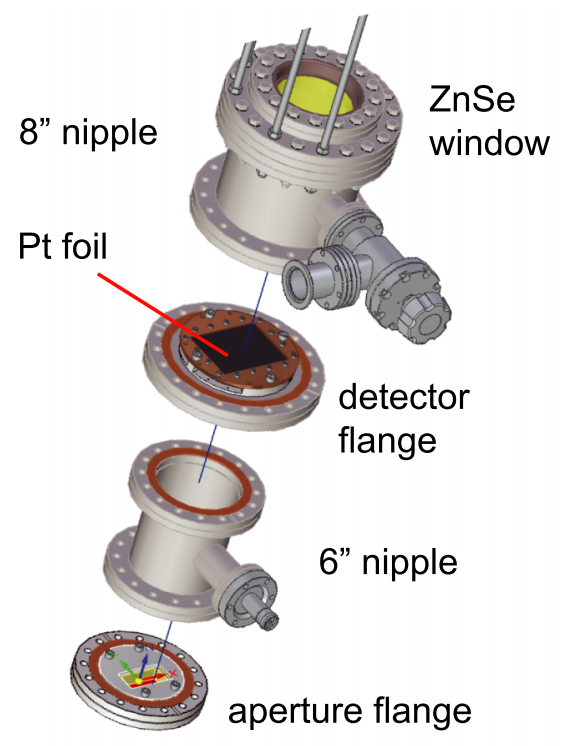

b) Installed Design

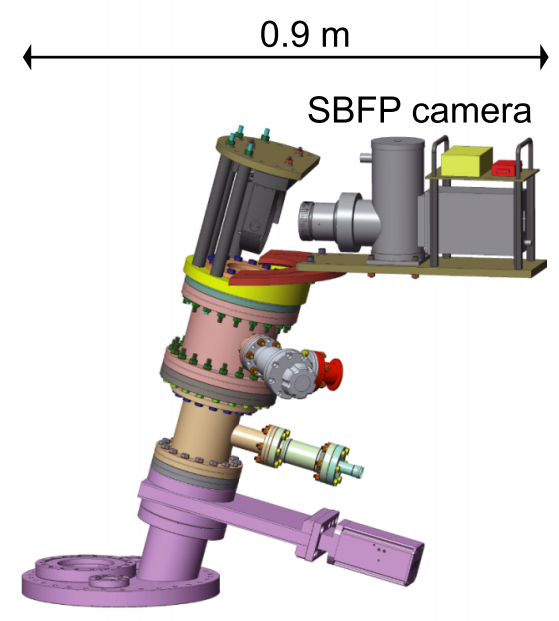

NSTX-U port c) NSTX-U IRVB FOV

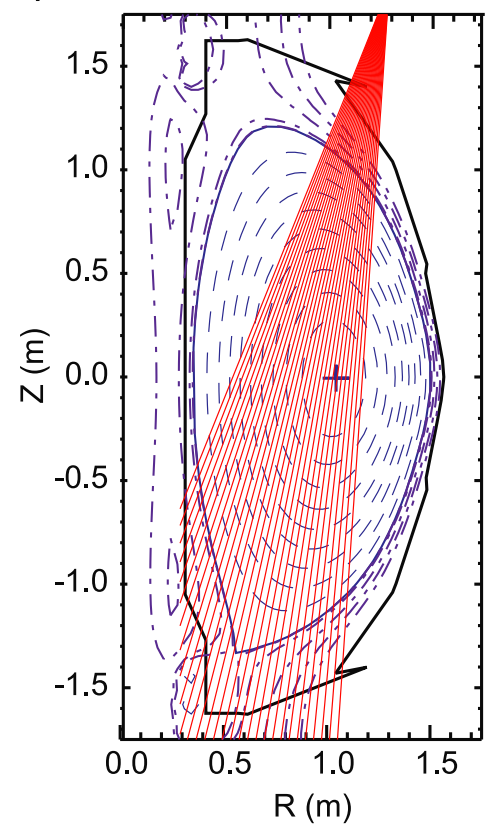

FIG. 1. Exploded design of the new prototype IRVB for NSTX-U (a). Installed design, including camera plate coupler and SBF-161 camera, connected to the gate valve (b). The FOV of the IRVB installed on the NSTX-U Bay-J upper port (c). The lines of sight for each IRVB super-pixel are shown relative to the 


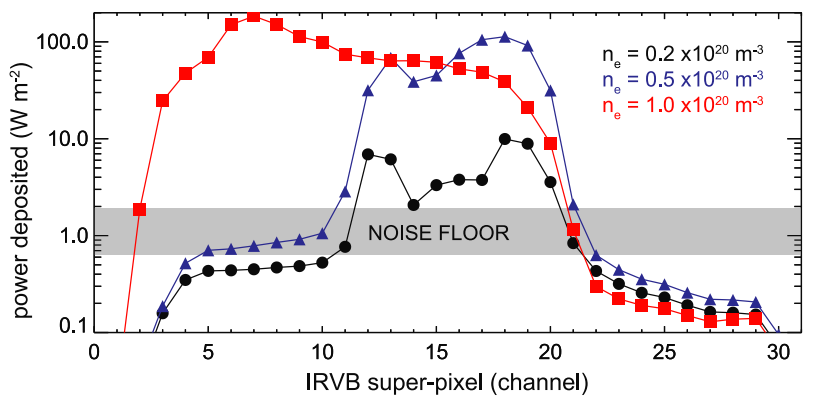

FIG. 2. Expected radiated power densities impinging on the IRVB superpixels from SOLPS modeling of a $10 \mathrm{MW}$ input power NSTX-U discharge.

reach $<1$ mTorr, low enough to neglect the effect of the foil cooling via conduction with air.

The diverging laser overfilled the IRVB aperture, leaving a rectangular irradiation pattern on the foil of power densities ranging 0.2-95 $\mathrm{W} \mathrm{m}^{-2}$, measured using a Thorlabs PDA36A. A systematic laser frequency and power scan were performed while the IR signal levels were measured by three different IR cameras with unique sensor technologies: FLIR A655sc (microbolometer), FLIR A6751sc (InSb detector), and SBF161 (MCT sensor). The laser frequency was varied from 0.2 to $150 \mathrm{~Hz}$ (square pulse) at a power density of $95.5 \mathrm{~W} \mathrm{~m}^{-2}$ during the FLIR A655sc test and $40.9 \mathrm{~W} \mathrm{~m}^{-2}$ during FLIR A6751sc and SBF-161 tests.

The IRVB SNR can be increased by both averaging over frames (reducing temporal resolution) and pixels (reducing spatial resolution). ${ }^{9}$ In order to effectively compare different cameras on their expected performance in an IRVB, frames were averaged as to obtain $\sim 200$ frames/s (fps) regardless of the camera frame rate while neighboring camera pixels were averaged yielding bolometer super-pixels of $\sim 1 / 8$ of the laser spot area. The camera specifications and subsequent bolometer performance after spatial and temporal averaging can be found in Table I. The number of IR pixels dedicated to image the foil relative to the total number of pixels was slightly different among the cameras, due to different lens characteristics and distance to the foil. The A6751sc and SBF-161 had a similar fraction of foil pixels to camera pixels while this fraction was $47 \%$ lower for the A655sc camera. In case of similar foil to detector fraction as the SBF-161 setup, $47 \%$ more pixels would have been attributed to image the laser spot, hereby increasing the A655sc performance by $\sqrt{1.47 \times 10 \times 10} / \sqrt{(10 \times 10)}$ $=1.21(1.02$ for $\mathrm{A} 6751 \mathrm{sc})$.

The raw IR signal increase measured by the IRVB superpixels during heating of the foil by the laser has been divided by the standard deviation of the signal without laser pulse, calculated over 50 frames to yield the SNR. Figure 3(a) shows

TABLE I. Characteristics of cameras tested for IRVB.

\begin{tabular}{lcccc}
\hline \hline & $\begin{array}{c}\text { Frame rate } \\
\text { (fps) }\end{array}$ & Pixel number & $\begin{array}{c}\text { Bolo frame rate } \\
\text { (fps) }\end{array}$ & Bolo super-pixels \\
\hline SBF-161 & 1610 & $128 \times 128$ & 200 & $4 \times 4$ \\
A655sc & 200 & $640 \times 120$ & 200 & $10 \times 10$ \\
A6751sc & 450 & $640 \times 128$ & 225 & $11 \times 11$ \\
\hline \hline
\end{tabular}
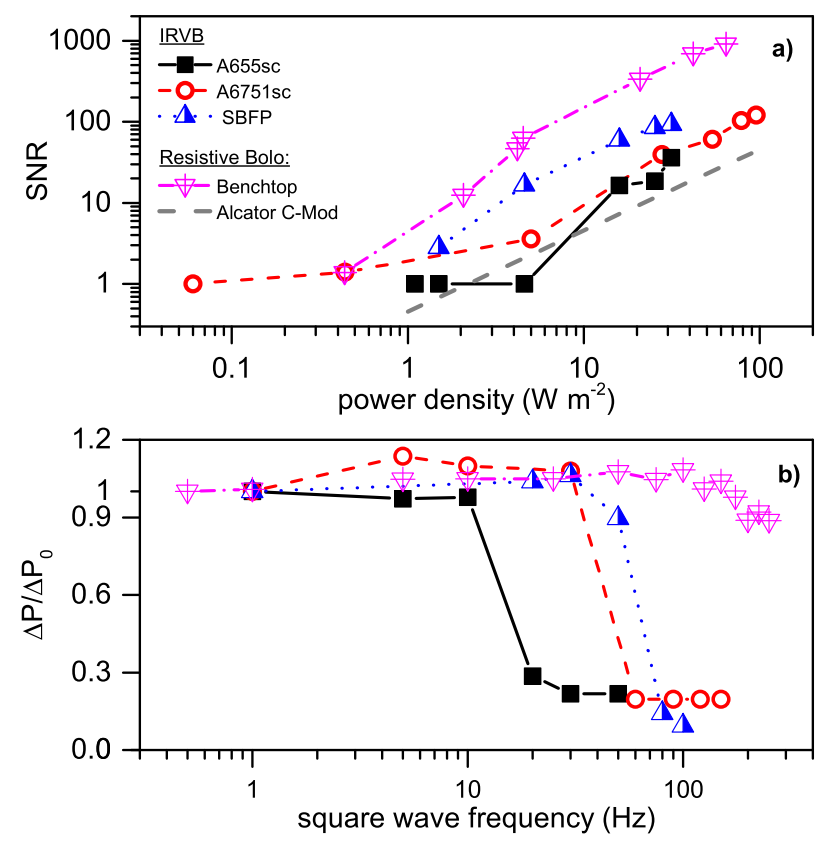

FIG. 3. SNR of the IR signals received by different cameras as function of incident power density from the laser (a). (b) shows the square wave signal increase $(\Delta \mathrm{P})$ normalized to the slowest pulse rate $\left(\Delta \mathrm{P}_{0}\right)$ versus laser frequency.

the results as function of laser power density while the IRVB was equipped with different cameras. The foil was heated by the laser during $1 \mathrm{~s}$. The A655sc camera shows a poor performance below $10 \mathrm{~W} \mathrm{~m}^{-2}$ (even when considering a factor 1.21 increase in sensitivity) whereas the SBF-161 is superior over the A6751sc in the measured range of 1.5-31.4 $\mathrm{W} \mathrm{m}^{-2}$. The SNR of both the A6751sc and SBF-161 cameras during benchtop testing is higher than that of resistive bolometers as deployed at Alcator C-Mod. ${ }^{7}$ The resistive bolometer sensitivity as measured on the benchtop, absent of the inherent electromagnetic interference in the tokamak test cell, is however roughly 4 times higher than that of the best IRVB performance.

The temporal shape of the radiated power absorbed by a single super-pixel can be approximated (neglecting spatial diffusion) by the proportionality: $P_{\mathrm{rad}} \propto P=S+\tau \partial S / \partial t$, where $S$ represents the raw IR count level while $\tau$ is the time constant. Similarly, for the resistive bolometer analysis, the measured bridge voltage is used for $\mathrm{S} . \Delta \mathrm{P}$ represents the difference between $\mathrm{P}$ during and prior to laser exposure. The laser pulse frequency was varied while $\Delta \mathrm{P}$ of a single, $200 \mathrm{fps}$, super-pixel was measured. As the laser power is held constant, $\triangle \mathrm{P}$ should be independent of frequency, provided the IRVB can temporally resolve the signals. The results are shown in Fig. 3(b) where $\Delta \mathrm{P}$ is normalized to the signal increase at slowest pulse rate $\left(\Delta \mathrm{P}_{0}\right)$ and compared between camera setups as well as that of the resistive bolometer. The ultimate time response of the resistive bolometer, digitized using standard IPT-Albrecht analyzer modules with a $1 \mathrm{kHz}$ low-pass filter, is not determined in the measured range. For the IRVB, varying signals up to $50 \mathrm{~Hz}$ can be reconstructed when equipped with the SBF-161 and A6751sc cameras. This is measurably lower than that of the resistive bolometer during lab testing but 
expected to be sufficient to discern between ELM and interELM phases in the type-I regime.

\section{CONCLUSION}

The development of a prototype IRVB for NSTX-U is completed and recently installed. Benchtop laser testing of the device has shown that the SNR is high enough to detect divertor radiation features as predicted by SOLPS modeling. Radiative features up to $50 \mathrm{~Hz}$ can be resolved using the SBF-161 camera while the SNR is competitive to resistive bolometers in a tokamak environment. Finally, benchtop laser testing has provided benchmark data of the noise levels and temporal response of the system equipped with three different IR cameras to be used for future IRVB designs.

\section{ACKNOWLEDGMENTS}

This work was carried out with financial support from NWO (the Netherlands) and the Department of Energy (USA) with Contract Nos. DE-AC05-00OR22725 and DE-AC0209CH114661. The authors wish to acknowledge Yury Malament, Robert Ellis, and Gustav Smalley (PPPL) for technical assistance and Dennis McCabe from FLIR Systems, Inc. for having camera models on loan.

${ }^{1}$ B. J. Peterson et al., J. Nucl. Mater. 415, S1147-S1150 (2011).

${ }^{2}$ B. J. Peterson et al., Rev. Sci. Instrum. 79, 10E301 (2008).

${ }^{3}$ M. Ono et al., Nucl. Fusion 55, 073007 (2015).

${ }^{4}$ B. J. Peterson et al., Rev. Sci. Instrum. 74, 2040 (2003).

${ }^{5}$ B. J. Peterson et al., Plasma Fusion Res. 5, 035 (2010).

${ }^{6}$ R. Sano et al., Plasma Fusion Res. 7, 2405039 (2012).

${ }^{7}$ M. L. Reinke et al., Rev. Sci. Instrum. 79, 10 F306 (2008).

${ }^{8}$ D. P. Coster et al., Phys. Scr. T104, 7 (2004).

${ }^{9}$ S. N. Pandya, Rev. Sci. Instrum. 85, 123501 (2014). 